\title{
DEMONSTRATION OF A TOXIC FACTOR IN THE BLOOD OF RATS SHOCKED BY BURN ${ }^{1}$
}

\author{
BY MYRON PRINZMETAL, H. C. BERGMAN, AND H. E. KRUGER \\ (From the Max Straus Research Laboratory, Cedars of Lebanon Hospital, Los Angeles)
}

(Received for publication March 4, 1946)

In previous studies published from this laboratory (1) it was shown that 2 major factors are implicated in the production of burn shock in mice and rats; the one, fluid loss at the site of the thermal injury, and the other, stagnation of blood in atonic visceral capillaries. Capillary atony was demonstrated in burn shock whether thermal trauma was accompanied by much or little local fluid loss. In certain forms of thermal injury there is very little edema formation (2); yet the circulatory blood volume as represented by the bleeding volume is drastically reduced and the animal dies in shock (1). In this instance, local fluid loss is eliminated as the principal cause of the reduction in the bleeding volume, and the pooling of blood in the capillary bed is chiefly responsible for the decrease in the effective circulating volume. In burn shock the number and diameter of open capillaries were found to be considerably increased $(1,3)$, and the amount of blood retained in the viscera significantly augmented. Atony of the capillary blood vessels is a primary disturbance since it develops within 2 minutes after a severe burn. Following mild burns, capillary atony persists in surviving animals for less than 24 hours. In order to demonstrate capillary congestion, controlled observations were made upon the hemoglobin content of visceral organs after exsanguinating the animal. There was little or no difference in the apparent degree of congestion in the burned and unburned animals when sacrificed by a method other than bleeding, but a striking difference was demonstrated after exsanguination. After bleeding, the organs of a normal unburned animal became pale and bloodless, whereas in burn shock the tissues remained dark and engorged.

A toxic factor has been previously demonstrated in experiments in which injection of blood from burned rats into normal rats caused a significantly

1 Aided by grants from the Blanche May Selden Fund, F. Brice, Morton May, and Mrs. J. Pressman. lower bleeding volume than injection of blood from normal animals (1). The studies reported in the present communication were undertaken to determine whether the perfusion of blood from a burned animal through a normal kidney would reproduce the capillary congestion which is characteristic of burn shock.

\section{METHODS}

Adult male, Long-Evans rats weighing 250 to 350 grams were anesthetized with ether. The pedicle of the right kidney in each test animal was tied and the kidney removed immediately by severing the pedicle distal to the ligature. Each animal received two $\mathrm{ml}$. of heparinized blood taken from burned rats. The blood was removed from the abdominal aorta of the anesthetized donor rats 3 to 4 minutes after they were burned to the neck at $100^{\circ} \mathrm{C}$. for 20 seconds, and injected into the abdominal aorta of the test rats just proximal to the origin of the renal artery. To facilitate the injecton, the needle was bent at an angle of approximately $120^{\circ}$. The abdominal aorta below the renal artery was momentarily compressed by the finger in order to insure the direct passage of the major portion of the injected blood through the left kidney (Figure 1). This procedure would seem to be more nearly physiologic than most standard methods of perfusion since the circulation is kept intact; the only departure from the normal being a temporary rise in the renal arterial pressure. Furthermore, a very high concentration of toxic factor would be expected to enter the perfused organ.

The left kidney in each of the test animals was removed immediately after perfusion and allowed to self-exsanguinate, and the hemoglobin content of both kidneys was determined. Thirty-eight control test rats prepared in precisely the same manner were given an injection of 2 ml. of heparinized blood from unburned animals.

The amount of hemoglobin in the kidneys was determined as follows. Hemoglobin was extracted with a buffered salt solution and measured photometrically after conversion to cyanmethemoglobin. The details are described in another publication (4). The reliability of the method was tested by making comparative estimations of like amounts of tissue taken from the same organ. These gave values within 5 per cent of one another.

In order to ascertain the number and diameter of open capillaries in the kidneys, duplicate sets of organs were 


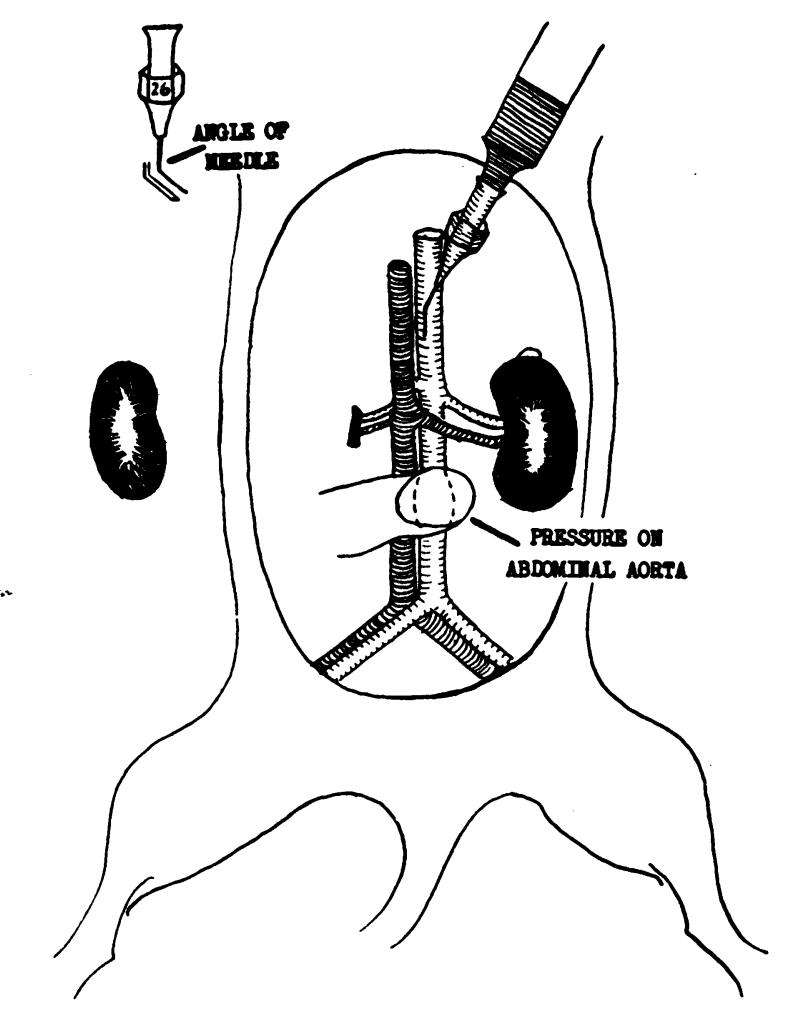

Fig. 1. Illustration of Method of Perfusing a KidNey With Blood

prepared for histologic examination. The method of preparation and staining of the sections was described in a previous publication (1).

\section{RESULTS}

In 38 rats, the kidneys which were perfused with normal blood were found to contain $1.20 \pm 0.039^{2}$ times as much hemoglobin as the unperfused kidneys. Manipulation of the kidney and the temporary rise in the renal arterial pressure during perfusion may explain the small increase in the hemoglobin content of the perfused kidney. In a parallel group of rats in which 1 kidney was perfused with blood from burned animals, the ratio of the hemoglobin content of the perfused kidneys to that of the unperfused kidneys was $1.54 \pm$ $0.074 .^{2}$ Since comparison of these ratios gives a $\mathrm{P}$ value of less than 0.001 , the difference of the mean values is statistically significant.

There is a striking difference in the gross appearance of the kidneys removed before and after injection of blood from a burned animal. The un-

\footnotetext{
2 Standard error of the mean.
}

perfused kidney self-exsanguinates rapidly and becomes pale and wrinkled, whereas the perfused kidney shows only minimal bleeding and presents a dark, engorged appearance. The perfused kidneys resemble kidneys taken from animals in shock. Kidneys perfused with normal blood do not differ in appearance from unperfused normal kidneys.

Table I shows the capillary counts in 2 animals injected with normal blood, and in 2 animals injected with blood from burned rats. In rats injected with normal blood, the average counts were 10.6 open capillaries in 10 standard fields (magnification 440) in the control kidney, and 8.2 open

TABLE I

Capillary counts in kidneys perfused with blood from normal and burned rats

\begin{tabular}{|c|c|c|c|c|c|}
\hline \multirow{2}{*}{ Perfusate } & \multicolumn{4}{|c|}{ Capillary counts* } & \multirow{2}{*}{$\begin{array}{l}\text { "P" } \\
\text { valuet }\end{array}$} \\
\hline & \multicolumn{2}{|c|}{ Control kidney } & \multicolumn{2}{|c|}{ Perfused kidney } & \\
\hline Normal blood & $\begin{array}{r}\text { mean } \\
11.3 \\
9.9\end{array}$ & $\begin{array}{c}\text { std. error } \\
\pm 1.4 \\
\pm 1.8\end{array}$ & $\begin{array}{r}\text { mean } \\
7.8 \\
8.6\end{array}$ & $\begin{array}{c}\text { std. error } \\
\pm 1.2 \\
\pm 1.7\end{array}$ & $\begin{array}{l}>0.05 \\
>0.6\end{array}$ \\
\hline $\begin{array}{l}\text { Blood from } \\
\text { burned rats }\end{array}$ & $\begin{array}{l}6.9 \\
7.2\end{array}$ & $\begin{array}{l} \pm 1.8 \\
\pm 1.3\end{array}$ & $\begin{array}{l}37.9 \\
23.9\end{array}$ & $\begin{array}{l} \pm 1.9 \\
\pm 1.6\end{array}$ & $\begin{array}{l}<0.001 \\
<0.001\end{array}$ \\
\hline
\end{tabular}

* Average number of open capillaries in 10 standard fields (magnification 440).

$t$ " $P$ " value of less than 0.05 indicates that the difference of the means is statistically significant.

capillaries in the perfused kidney. The corresponding values in rats injected with blood from burned animals were 7.1 and 30.9, respectively. The renal capillaries in animals which received blood from burned rats were abnormally dilated, and contained many more cells than those in animals which received normal blood (Figure 2).

\section{DISCUSSION}

In previous investigations (1) an atonic state of the vessels of the capillary bed leading to visceral congestion has been shown to be one of the primary factors in the initiation of the shock syndrome in scalded animals. Capillary congestion was especially prominent in the kidneys, liver, heart, intestine, and adrenal glands of the shocked animals, and could be demonstrated within a few minutes after a severe burn (1). Briefly stated, the results of the experiments described in this communication indicate that perfusion of a rat's kid- 


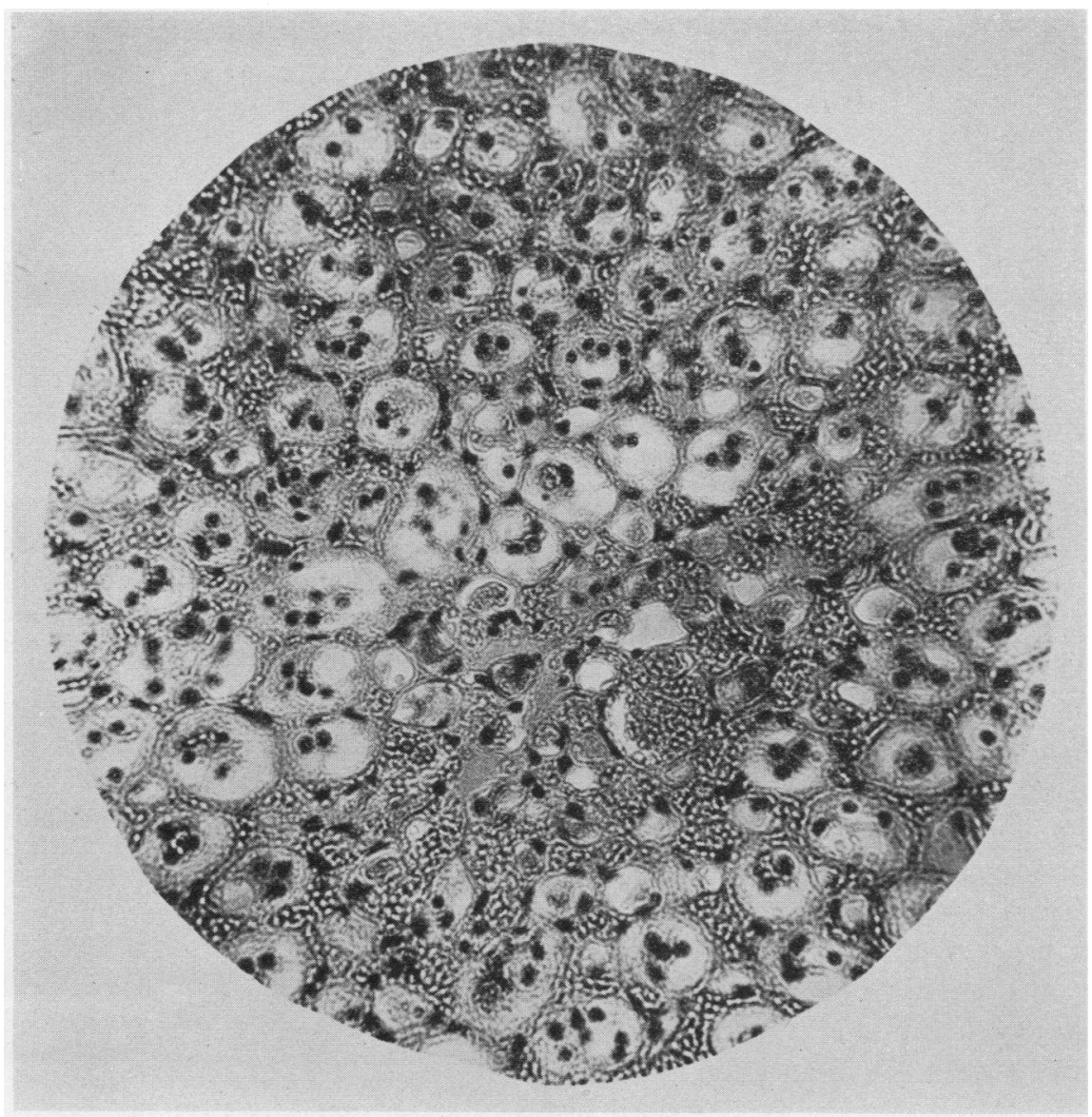

Fig. 2. Photomicrograph Showing Open and Dilated Capillaries in Medullary Region of Rat Kidney following Perfusion with Blood from a Burned Rat (magnification 440)

ney with blood from a burned animal reproduces the capillary congestion which is characteristic of burn shock. Since capillary atony can be induced in a normal rat either by a burn or by the injection of blood from a burned animal, it is reasonable to conclude that the capillary congestion is due to a toxic factor which circulates in the blood of a burned animal. It is important to emphasize that this factor is not necessarily a newly formed substance; it may represent merely a change in the concentration or in the physical state of a normal blood constituent. Of interest in this respect are the observations of Shen, Ham and Fleming, who demonstrated changes in the morphology and osmotic fragility of red blood cells after thermal burns in human beings (5). There have been recent reports on the presence of toxic substances in other forms of shock (6 to 10$)$.

Recently, Chambers, Zweifach, and their associates (11 to 13 ), investigating vascular reactions in shock, described 2 phases, the second of which was characterized by a progressive decrease in the constrictor activity of metarterioles and precapillary sphincters. Sequestration of blood from the active circulation by pooling in the capillary bed would lead eventually to failure of the venous return to the heart.

Zweifach (14) showed that 2 types of blood capillaries could be distinguished according to whether muscular elements are present or absent in their walls. These are (1) the arteriolovenular capillaries ("muscular capillaries") and (2) the true capillaries ("non-muscular capillaries"). 
Both types of capillaries possess tone, and in the latter the presence of tone must be ascribed to the endothelial cells that comprise its wall. It cannot be denied that the capillaries respond passively to tonic changes in the metarterioles and precapillary sphincter musculature, but the participation of active changes in the tone of the capillaries themselves cannot be excluded as a factor capable of influencing their calibre. The degree of selfexsanguination of an extirpated organ in the normal and shocked animal, respectively, throws light upon the question of whether the true capillaries actively participate in the emptying of the capillary bed. If, for instance, a kidney is removed by severing the renal pedicle, the organ promptly self-exsanguinates, and it would appear highly improbable that the capillary bed could be emptied to so great an extent without active contraction of the capillaries themselves. On the other hand, a kidney removed from a shocked animal retains almost all of its blood, and the remarkable degree of dilatation and congestion of all the vessels in the capillary bed as shown in the histologic sections is not easy to explain, unless it is assumed that the true capillaries have suffered a loss of tone.

It is not at all certain that the toxic factor postulated in the present communication is identical with the vasodepressor principle described by Chambers and his associates (11 to 13), and the question of their relationship remains for future studies to determine.

\section{SUMMARY}

1. A simple physiologic method of renal perfusion is described.

2. Perfusion of the normal rat's kidney with blood taken from a burned rat reproduces the toxic capillary atony which is characteristic of burn shock.

\footnotetext{
The authors wish to extend their thanks to Dr. Benjamin Sacks for his valuable aid in the preparation of this manuscript.
}

\section{BIBLIOGRAPHY}

1. Prinzmetal, M., and Bergman, H. C., The nature of circulatory changes in burn shock. Clin. Science, 1945, 5, 205.

2. Prinzmetal, M., Bergman, H. C., and Hechter, O., A demonstration of two types of burn shock. Surgery, 1944, 16, 906.

3. Prinzmetal, M., and Bergman, H. C., The heart in experimental shock. J. Mt. Sinai Hospital, 1945, $12,579$.

4. Bergman, H. C., and Prinzmetal, M., The antishock action of ethanol in burned mice. Effect on edema formation and capillary atony. J. Lab. and Clin. Med., 1946, 31, 654.

5. Shen, S. C., and Ham, T. H., Studies on the destruction of red blood cells. III. Mechanism and complications of hemoglobinurea in patients with thermal burns: Spherocytosis and increased osmotic fragility of red blood cells. New England J. Med., 1943, 229, 701.

6. Blalock, A., Study of thoracic duct lymph in experimental crush injury and injury produced by gross trauma. Bull. Johns Hopkins Hosp., 1943, 72, 54.

7. Aub, J. C., and others, Bacteria and the "toxic factor" in shock. War Med., 1944, 5, 71.

8. Prinzmetal, M., Freed, S. C., and Kruger, H. E., Pathogenesis and treatment of shock resulting from crushing of muscle. War Med., 1944, 5, 74.

9. Chess, S., Chess, D., and Cole, W. H., Experimental tourniquet shock with particular reference to the toxic factor; method of production eliminating influence of general anesthesia and nervous influences. Arch. Surg., 1944, 49, 147.

10. Rapport, D., Guild, R., and Canzanelli, A., Transmission by crossed circulation of shock producing factor. Am. J. Physiol., 1945, 143, 440.

11. Zweifach, B. W., Lee, R. E., Hyman, C., and Chambers, R., Omental circulation in morphinized dogs subjected to graded hemorrhage. Ann. Surg., 1944, $120,232$.

12. Zweifach, B. W., Abell, R. G., Chambers, R., and Clowes, G. H. A., Role of the decompensatory reactions of peripheral blood vessels in tourniquet shock. Surg. Gynec. and Obst., 1945, 80, 593.

13. Shorr, E., Zweifach, B. W., and Furchgott, R. F., On the occurrence, sites and modes of origin and destruction, of principles affecting the compensatory vascular mechanisms in experimental shock. Science, 1945, 102, 489.

14. Zweifach, B. W., The character and distribution of the blood capillaries. Anat. Rec., 1939, 73, 475. 